\title{
THE CORRELATION OF COUPLED HEAT AND MASS TRANSFER EXPERIMENTAL DATA FOR VERTICAL FALLING FILM ABSORPTION
}

\author{
William A. Miller, Ph.D., Research Engineer \\ Oak Ridge National Laboratory+ \\ Oak Ridge, TN 37831 \\ Majid Keyhani, Ph.D., Professor \\ Mechanical \& Aerospace Engineering and Engineering Science Department \\ University of Tennessee, Knoxville
}

\begin{abstract}
Absorption chillers are gaining global acceptance as quality comfort cooling systems. These machines are the central chilling plants and the supply for comfort cooling for many large commercial buildings. Virtually all absorption chillers use lithium bromide ( $\mathrm{LiBr}$ ) and water as the absorption fluids. Water is the refrigerant. Research has shown $\mathrm{LiBr}$ to he one of the best absorption working fluids because it has a high affinity for water, releases water vapor at relatively low temperatures, and has a boiling point much higher than that of water. The hcart of the chiller is the absorber, where a process of simultaneous heat and mass transfer occurs as the refrigerant water vapor is ahsorhcd into a falling film of aqueous $\mathrm{LiBr}$. The more water vapor absorbed into the falling film, the larger the chiller's capacity for supporting comfort cooling. Improving the performance of the absorber leads dircctly to efficiency gains for the chiller.

The design of an absorber is very empirical and requires experimental data. Yet design data and correlations arc sparse in the open literature. The experimental data available to date have been derived at $\mathrm{LiBr}$ concentrations ranging from 0.30 to 0.60 mass fraction. No literature data are readily available for the design operating conditions of 0.62 and 0.64 mass fraction of $\mathrm{LiBr}$ and absorber pressures of 0.7 and $1.0 \mathrm{kPa}$.
\end{abstract}

\footnotetext{
${ }^{\dagger}$ Managed by Lockheed Martin Energy Research Corporation under Cuntract DE-AC05-960R22464 for the U.S. Department of Energy.
}

The submitted manuscript has been authored by a contractor of the U.S. Government under contract No. DE-AC05-96OR22464. Accordingly, the U.S. Government retains a noncxclusive, royalty-free license to publish or reproduce the published form of this contribution, or allow others to do so, for U.S. Government purposes.
Experiments wcre conducted on an internally cooled smooth tube $0.01905 \mathrm{~m}$ in outside diameter and $1.53 \mathrm{~m}$ in length. Tests were conducted with no heat and mass transfer additive. The data, for testing at 0.62 and 0.64 mass fraction of $\mathrm{LiBr}$, were scaled and correlated into both Nusselt (Nu) and Sherwood (Sh) formulations. The avcrage absolute error in the Nusselt correlation is about $\pm 3.5 \%$ of the $\mathrm{Nu}$ number reduced from the experimental data. The Sherwood correlation is about $\pm 5 \%$ of the reduced Sh data. Data from the open literature were reduced to the authors' $\mathrm{Nu}$ and $\mathrm{Sh}$ formulations and were within $5 \%$ of the correlations developed in the present study. Hence, this study provides correlations for the complex heat and mass transfer process that is validated against extensive experimental data. The study therefore contains useful information for the design of a vertical column absorber operating with no heat and mass transfer additive.

\section{INTAODUCTION}

The capacity of a chiller-or more spccifically, the evaporator load-is directly proportional to the mass of refrigerant assimilated in the absorber. Improving the absorber's transport processes increases the chiller's capacity to support comfort cooling. The absorber is the largest of the machine's heat cxchangers, and in the past its design was based on rules of thumb, resulting in heavy. costly, and overdesigned equipment. The design was created through a semi-empirical approach based on log-mean tcmperature difference. Experiments would he conducted and an empirical map would he derived for the overall heat transfer coefficient and the absorber load. The results were scaled to the desired machine capacity bascd on the experimental data as well as on the experience of the designer. Changing absorber configuration elements such as tubc spacing, diameter, 
NOMENCLATURE

\begin{tabular}{|c|c|c|}
\hline SYMBOL & DESCRIPTIVE & SI UNITS \\
\hline A & Area & $\mathrm{m}^{2}$ \\
\hline $\mathrm{C}_{\mathrm{a}}$ & Concentration of absorbate & g-mole $\mathrm{H}_{2} \mathrm{O} / \mathrm{cc}$ soln \\
\hline $\mathrm{C}_{\mathrm{p}}$ & Specific heat & $\mathrm{kJ} / \mathrm{kg} \cdot \mathrm{K}$ \\
\hline$D, d$ & Pipe diameter & $\mathrm{m}$ \\
\hline $\mathrm{D}_{A B}$ & Diffusivity of a through $b$ & $\mathrm{~m}^{2} / \mathrm{s}$ \\
\hline $\mathrm{g}$ & Gravity & $\mathrm{m}^{2} / \mathrm{s}$ \\
\hline $\mathbf{H}_{\mathrm{m}}$ & Overall liquid-side mass transfer coefficient & $\mathrm{m} / \mathrm{s}$ \\
\hline $\mathrm{H}$ & Overall heat transfer coefficient & $J / \mathrm{m}^{2} \cdot \mathrm{K} \cdot \mathrm{s}$ \\
\hline $\mathbf{i}_{\mathrm{fg}}$ & Latent heat of water vapor & $\mathrm{kJ} / \mathrm{kg}$ \\
\hline $\mathrm{k}$ & Thermal conductivity & $\mathrm{J} / \mathrm{m} \cdot \mathrm{K} \cdot \mathrm{s}$ \\
\hline $\mathrm{m}$ & Mass flow rate & $\mathrm{kg} / \mathrm{s}$ \\
\hline$\dot{\mathrm{m}}^{\prime \prime}$ & Absorbate mass flux & $\mathrm{kg} / \mathrm{m}^{2}$ \\
\hline$q$ & Heat transfer rate & $\mathrm{J} / \mathrm{s}$ \\
\hline$q^{\prime \prime}$ & Heat flux & $J / m^{2}$ \\
\hline$P_{y}$ & Absorber pressure & $\mathrm{kPa}$ \\
\hline $\mathrm{T}$ & Temperature & "C \\
\hline$\overline{\mathrm{U}}$ & Average falling film velocity & $\mathrm{m} / \mathrm{s}$ \\
\hline $\mathrm{x}$ & Coordinate in direction of flow & $\mathrm{m}$ \\
\hline Y & Coordinate normal to direction of flow & $\mathrm{m}$ \\
\hline A & Average film thickness & $\mathrm{m}$ \\
\hline$\delta$ & Film thickness as function of $t, x$, and $y$ & $\mathrm{~m}$ \\
\hline $\mathrm{P}$ & Density & $\mathrm{g} / \mathrm{cc}$ \\
\hline$\eta^{\prime}$ & Molecular weight of water & $\mathrm{g} / \mathrm{g}$-moles \\
\hline$v$ & Kinematic viscosity & $\mathrm{m}^{2} / \mathrm{s}$ \\
\hline$\mu$ & Dynamic viscosity & $\mathrm{kg} / \mathrm{m} \cdot \mathrm{s}$ \\
\hline $\mathrm{X}$ & Mass fraction & $\mathrm{kg} \mathrm{LiBr} / \mathrm{kg}$ soln \\
\hline a & Surface tension & $\mathrm{N} / \mathrm{m}$ \\
\hline & & \\
\hline $\mathrm{CL}$ & Coolant & \\
\hline eq & Equilibrium & \\
\hline $\mathrm{ex}$ & Exit & \\
\hline $\mathrm{f}$ & Film & \\
\hline in & Inlet & \\
\hline & Maximum & \\
\hline 0 & Outside diarneter or outside radius & \\
\hline $\mathrm{v}$ & Absorbate vapor & \\
\hline wall & Tube wall & \\
\hline
\end{tabular}

Dimensionless Groups

$\begin{array}{cl}\varepsilon & \text { Aspect ratio } \\ \mathrm{Ja} & \text { Jacobs number } \\ \mathrm{Ka} & \text { Kapitza number } \\ \mathrm{Le} & \text { Lewis number } \\ \mathrm{Nu} & \text { Nusselt number }\end{array}$

$\varepsilon=\delta / x$
$\mathrm{C}_{\mathrm{P}} \Delta \mathrm{T}$
$\mathrm{i}_{\mathrm{fg}}$
$\sigma$

$\rho\left(v^{4} g\right)^{\frac{1}{3}}$

$\frac{\alpha}{D_{\mathrm{ab}}} \equiv \frac{\mathrm{SC}}{\mathrm{Pr}}$

$\frac{\mathrm{HD}_{0}}{\mathrm{k}_{\mathrm{f}}}$ 


$\begin{array}{llr}\mathrm{Pe}_{\mathrm{H}} & \text { Peclet heat } & \frac{4 \overline{\mathrm{U}} \Delta}{\frac{\alpha}{\alpha}} \equiv \operatorname{Re} \cdot \operatorname{Pr} \\ \mathrm{Pe}_{\mathrm{M}} & \text { Peclet mass } & \frac{4 \overline{\mathrm{U}} \Delta}{\mathrm{D}_{\mathrm{ab}}} \equiv \operatorname{Re} \cdot \mathrm{Sc} \\ \mathrm{Pr} & \text { Prandtl number } & \frac{\mathrm{C}_{\mathrm{p}} \mu}{\frac{\mathrm{k}}{4 \overline{\mathrm{U}} \Delta}} \equiv \frac{v}{\alpha} \\ \mathrm{Re} & \text { Reynolds number } & \frac{4 \dot{\mathrm{m}}}{\pi \mathrm{D} \mu} \\ \mathrm{SC} & \text { Schmidt number } & \frac{v}{\mathrm{D}_{\mathrm{ab}}} \\ \mathrm{Sh} & \text { Sherwood number } & \underline{\mathrm{H}_{\mathrm{m}} \mathrm{D}_{0}}\end{array}$

length, and material, or changing the operating conditions would invalidate the design; and experiments would be rerun to redevelop the empirical map.

Over the last three decades several researchers have analytically investigated simultaneous heat and mass transfer. Emmert and Pigford (1954) developed an approximate solution for isothermal mass transfer. Grigor'ycva and Nakoryakov (1977) and later Grossman (1983) analytically solved the energy and specie equations for the heat and mass transfer to a laminar falling film having a constant temperature or an adiabatic wall boundary condition. Wekken and Wassenaar (1988), Habib and Wood (1990), and Yang and Wood (1992) completed numerical studies that either complemented or furthered the earlier work on laminar falling film absorption. Morioka and Kiyota (1991), Yang and Jou (1993), Patnaik (1994), Kim et al. (1995), Conlisk (1995), and Patnaik and Perez-Blanco (1996) each completed analytical studics of the wavy laminar problem.

In all these studies the analysts assumed the liquid-vapor interface to he saturated at the pressure of the vapor in order to solve the problem. In some studies, transport coefficients were gleaned from such works as Bays and McAdams (I 973) for heat transfer and Yih and Chen (1982) for mass transfer. The approach used by Patnaik and Percz-Blanco (1996) required local heat and mass transfer coefficients to characterize the transport associated with the local flow conditions.

The formulation for the liquid-vapor boundary conditions has received much discussion. At issue is the cxchange of mass across the liquid-vapor interface, which involves the generation of heat. Water has a large heat of absorption-about $2700 \mathrm{~kJ} / \mathrm{kg}$ - and heat effects associated with the mass exchange increase the temperature, which affects the pressure and composition and in turn affects the mass transfer. Aqueous $\mathrm{LiBr}$ is a homogenous, real mixture that requires empirical data to quantify its pressure, temperature, and composition. Hence, mixing rules for ideal mixtures are not applicable for calculating non-equilibrium conditions, further complicating the complex interface boundary condition. Without a priori knowledge of the local variations of heat and mass transport, researchers assumed equilibrium to be the best approximation to the actual condition. The findings by Miller (1998) on the constant flux boundary simplify the solution because they imply that the local temperature gradient from the coolant to the interface remains approximately constant along the length of an absorber tubc.

Miller (1998) also showed that the heat transfer affected the mass transfer coefficient, and that therefore a mass transfer coefficient derived from isothermal testing would not adequately describe simultaneous heat and mass transfer. The local mass transfer coefficient decreased while the heat transfer coefficient increased as the film transitioned into fully developed hydrodynamic flow. In fact. the use of independent heat and mass transfer coefficients actually decouples the transport. The more cxothermic the heat release, the larger the temperature gradient through the liquid phase. Hcat flows through the film and further influences the thermodynamic equilibrium, which in turn affects the mass transfer. The greater the heat effect achievable, the lower will be the concentration gradient available for mass transfer. Conlisk (1995) showed analytically that as the inlet film thins, the mass transfer coefficient decreases and the heat transfer coefficient increases. Therefore, approaching the problem with independently derived transport cocfficients can be misleading in evaluating the load and the mass absorbed.

The problem was therefore approached from an ovcrall rather than from a local perspective. A correlation was formulated by using the flows, temperatures, and concentrations entering and exiting the absorber to avoid the uncertainties in the local variations of the interface temperature and concentration. The correlation also used the tube diameter rather than the film thickness to avoid the confounding effect of the film's hydrodynamics. Hence, a correlation of simultaneous heat and mass transfer was formulated that is based on overall heat and mass transfer coefficients. The overall coefficients are derived from the absorber load and the mass absorbed. Given the findings of a constant flux boundary reported by Miller, the correlation can be scaled to the specific length and diameter of absorber tubes. 
Validation of the correlation against cxtensive experimental data follows in the text of this report.

\section{EXPERIMENTAL SETUP}

A single absorber tube with a 0.01905-m outside diameter and a length of I.524 m was tested to obtain baseline data for the purposes of formulating correlations of heat and mass transfer. Testing was conducted over a range of operating conditions that included near-field conditions for residential and commercial systems. In air-cooled applications the operating conditions would be about $62 \mathrm{wt} \% \mathrm{LiBr}$, with an absorber pressurc of about $1.5 \mathrm{kPa}$ and an inlet cooling water temperature of about $46^{\circ} \mathrm{C}$. Testing was also conducted at a cooling water temperature of $35^{\circ} \mathrm{C}$ to simulate load rejection to a cooling tower. In commercial equipment, some of the solution leaving the absorber is circulated back and mixed with strong solution $\mathrm{t}$ ) improve wetting of the absorber tubes. Thus, the nct concentration entering the absorber is about 60 to $62 \mathrm{wt} \%$. Testing was thereforc conducted at 60,62 , and $64 \mathrm{wt} \%$, for absorber pressures of $1.5,1.3$, and $1.0 \mathrm{kPa}$, to also characterize operating conditions for commercial application.

\section{UNCERTAINTY ANALYSIS}

An uncertainty analysis was conducted to determine the maximum error for the load and the mass absorbed. Since the true value of a given measurcment is not directly known, it is more accurate to speak of experimental uncertainty than of experimental error. The uncertainty analysis accounts for both the random error and the systematic error. Random error is duc to the lack of repeatability and therefore describes the precision of measurement. Statistics are applied to the random error to establish measurement hands within which replication of measurement is assured to a given conlidence interval. Systematic error is the bias from the truc measurement and describes the inaccuracy of a calibration procedure. Miller (1998) gives the derivation and calculation of the uncertainty in ahsorhcr load and the mass ahsorhed.

The uncertainty in the absorber load measurcd on the coolant side was $\pm 7.0 \%$ at $95 \%$ confidence. As expected, the major error in the load was duc to the temperature gain of the coolant. The average uncertainty in the mass absorbed for all the reported experimental data is $\pm 25 \%$ al $95 \%$ confidence. Note that the uncertainty analysis indicates the maximum possible error in the data. Mcasurements on the brine side and the coolant side showed the calculated heat balance within about $10 \%$ agreement.

\section{ABSORPTION TEST RESULTS}

We established the independent parameters of flow, temperature, concentration, and pressure to start testing. Flow rate was the easiest variable to change, and therefore the effects of the other variables were tested one parameter at a time for falling film mass flows ranging from 0.014 to $0.026 \mathrm{~kg} / \mathrm{s}$ (Re numbers of 100 400). The load is defined as the heat removed from the absorber by the coolant; it is plotted in Fig. 1. The increase in load is directly related to the mass of vapor absorbed into the falling film; it is plotted in Fig. 2. The more vapor absorbed, the greater the capacity of a chiller's evaporator. Absorber load. then, is a good indicator of system performance, although the mass ahsorhed is the important variable.

Stable wavy-laminar roll waves and, at the highest flows, second-transition turbulent laminar roll waves were observed during testing. The inception of the waves appeared to be

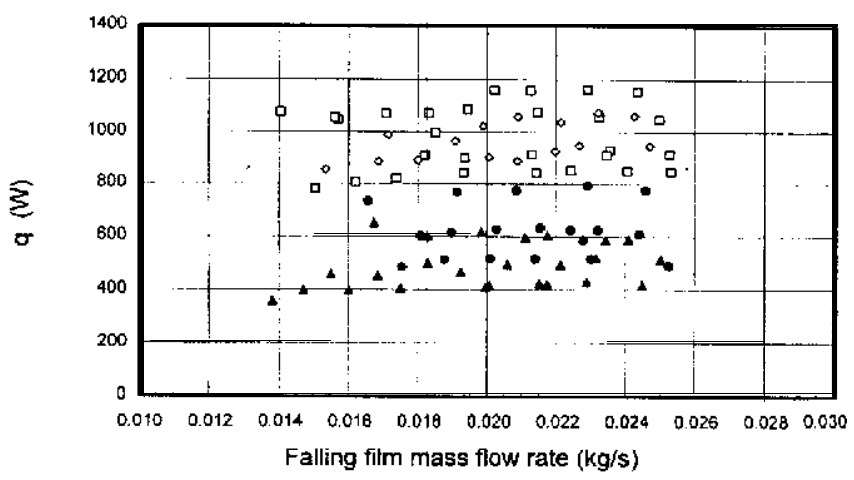

$$
\begin{aligned}
& \text { 0 } 62 \text { wt\%, } 35^{\circ} \mathrm{C} \text { Coolant } \\
& 060 w t \%, 35^{\circ} \mathrm{C} \text { Coolant } \\
& -64 w+\%, 46^{\circ} \mathrm{C} \text { Coolant } \\
& -62 w+\%, 46^{\circ} \mathrm{C} \text { Coolant }
\end{aligned}
$$

Fig. 1. Absorber load as a function of concentration, pressure, coolant temperature, and falling film mass flow rate.

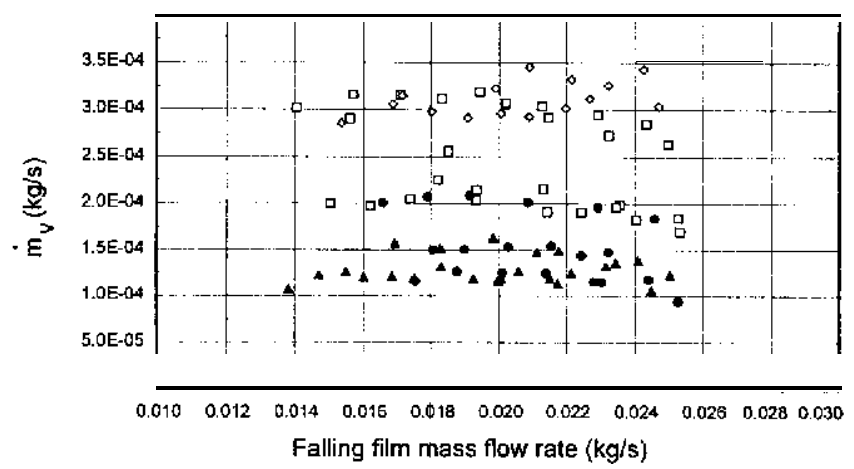

$$
\begin{aligned}
& \text { - } 62 \text { wt\%, } 355^{\circ} \mathrm{C} \text { Coolant } \\
& -60 \text { wt\%, } 35^{\circ} \mathrm{C} \text { Coolant } \\
& \text { - } 64 \text { wt\%, } 46^{\circ} \mathrm{C} \text { Cookant } \\
& \text { \& } 62 \text { wt\%, } 46^{\circ} \mathrm{C} \text { Coolant }
\end{aligned}
$$$$
\text { - }
$$

Fig. 2. Mass absorbed as a function of concentration, pressure, coolant temperature, and falling film mass flow rate. 
influenced by the solution flow rate. At the lowest flow of $0.014 \mathrm{~kg} / \mathrm{s}$, the inception of short waves of small amplitude were seen about $0.2 \mathrm{~m}$ from the inlet. The short waves transition into a longer roll-wave whose length and amplitude were at least twice those of the short wave. The results show that the mass absorbed and the load are not strongly affected by the falling film mass flow rate. Increasing the mass flow rate of the falling film shows an effect only at the lowest flow rates. These relatively flat data differed from the results of Grossman and Alefeld (1996), who tested at a higher absorber pressure of $8.7 \mathrm{kPa}$, and introduced the solution into the absorber with about 15 to $20^{\circ} \mathrm{C}$ of subcooling. For the present study, the solution entered the absorber saturated at about the operating pressure for chiller equipment.

The data are separated and plotted in Fig. 3 to better indicate the effects of absorber pressure, concentration, and coolant temperature. Pressure and concentration both have strong effects on the mass absorbed. Testing at $64 \mathrm{wt} \% \mathrm{LiBr}$ and $46^{\circ} \mathrm{C}$ coolant showed the mass absorbed to increase by almost $200 \%$ as the pressure was increased from 1 to $1.5 \mathrm{kPa}$ [Fig. 3(a)]. Similar increases in mass absorbed were observed when the concentration was increased from 60 to $64 \mathrm{wt} \% \mathrm{LiBr}$ for a coolant temperature of $46^{\circ} \mathrm{C}$ and pressure of $1.5 \mathrm{kPa}$ [Fig. 3(h)]. For testing at $62 \mathrm{wt} \%$ and $1.3 \mathrm{kPa}$ pressure, a decrease in coolant temperature from 46 to $35^{\circ} \mathrm{C}$ also caused the mass absorhed to nearly double [Fig. 3(c)].

In the absence of non-condensahles, the resistance in the vapor phase is negligible, allowing the vapor pressure to he imposed on the interface. The driving force for absorbing the water vapor into the falling film is then the difference between the pressure of the ahsorhcr vapor on the interface and the partial pressure of the absorbate water in the liquid-vapor interface. Obviously, the driving force increases with an increase in the absorber pressure. The driving force would also increase as the concentration of $\mathrm{LiBr}$ increases. The higher the $\mathrm{LiBr}$ concentration, the lower the partial pressure of water in the brine, and therefore the greater the driving force for mass transfer. Lowering the cooling water temperature causes a stecper approach temperature for the falling film. The interface temperature drops, which lowers the partial pressure of water vapor within the interface. The driving potential then increases, in turn increasing the mass absorbed and the load. Hence, the plots shown in Fig. 3 are consistent with absorption theory. However, once the vapor has been absorbed, the driving force is liquid-side-controlled because of the high resistance to mass diffusion. After absorption, the mass transfer driving force is defined in terms of the difference in concentration between the interface and the bulk of the film. The higher the bulk concentration of $\mathrm{LiBr}$, the larger this liquidside driving force and the more mass absorbed into the bulk. The absorbate tends to lie on the interface, and continued mass transfer requires a cooling of the interfacc. The results show the coupling between mass transfer and heat transfer that is tied to the composition of the interface, the diffusion of absorbate from the

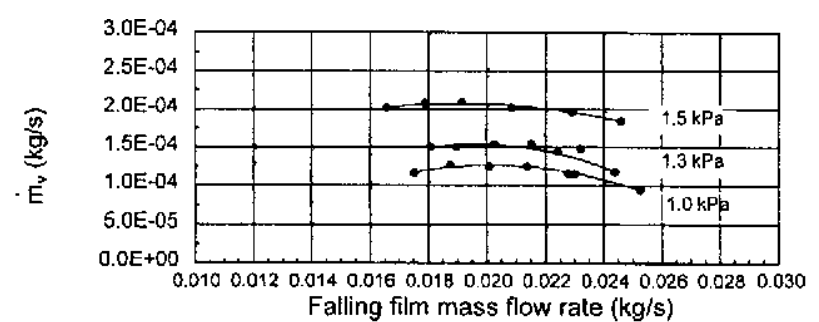

(a) The effect of vapor pressure for $64 \mathrm{wt} \% \mathrm{LiBr}$ and $46^{\circ} \mathrm{C}$ coolant.

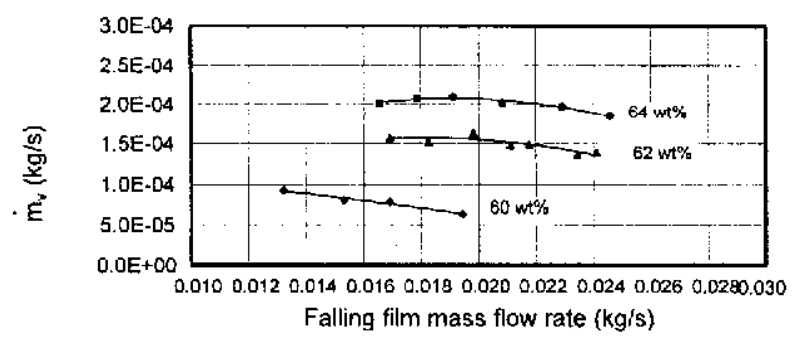

(b) The elfect of concentration for $1.5 \mathrm{kPa}$ vapor pressure and $46^{\circ} \mathrm{C}$ coolant

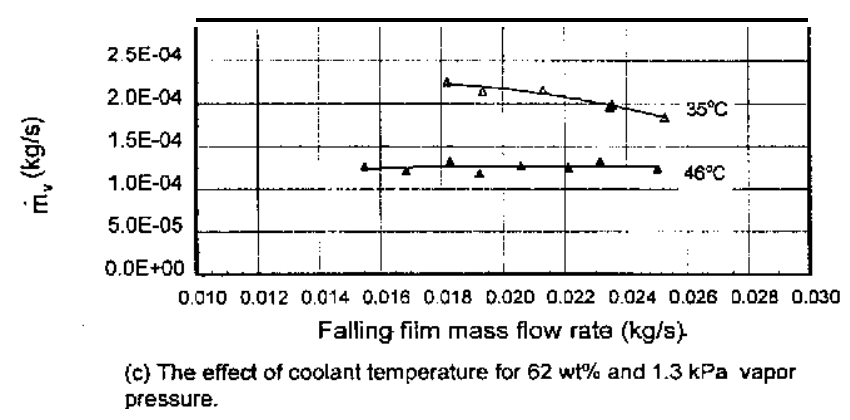

Fig. 3. The effect of the independent variables of pressure, concentration, and coolant tempearture on mass absorbed.

interface, and most important, the transfer of heat from the interface.

\section{Formulation of Nu and Sh Numbers}

Grigor'yeva and Naroryakov (1977). Seban and Faghri (1978), and Grossman (1982) developed heat and mass transfer correlations by solving the energy and diffusion equations using the classical Gratz-Nusselt approach in which hoth diffusion and conduction are neglected in the direction of flow. Their correlations typically take the form

$$
\mathrm{Nu}=\mathrm{f}\{\operatorname{Re}, \operatorname{Pr}, \varepsilon\} \text { and } \mathrm{Sh}=\mathrm{f}\{\operatorname{Re}, \mathrm{Sc}, \varepsilon\}
$$

The $\mathrm{Nu}$ and Sh formulations account for the effects of viscosity, diffusivity, and inertia; hut the coupled heat and mass transfer process has very strong prcssurc, concentration, and temperature effects, as seen in Fig. 3. Yang and Jou (1993) 
accounted for the cflect of pressure by including in Eq. I a pressure term normalized to the arbitrary vapor pressure of $1.133 \mathrm{kPa}$. The formulations in Eq. 1 do not explicitly account for the effect of concentration and pressure. Therefore, accurate correlation of simultaneous heat and mass transfer data requires a judicious selection of the temperature and concentration driving forces.

\section{Heat Transfer}

In conventional equipment, superheated brine is sprayed over an ahsorher tube bundle. As a spray, the brine flashes and is driven to equilibrium with the absorber pressure; it is saturated when it hits the first ahsorher tubes. In the mini-absorber used in the test stand, brine entered either slightly superheated or slightly subcooled. To simulate conventional operation, the dispenser was fabricated with vapor ports to allow the hrine the opportunity to equilibrate before being introduced to coupled heat and mass transfer. Because the brine was initially saturated, the driving force was well defined at the top of the absorber tube. Miller (1998) describes an algorithm used to calculate the entering interface temperature and concentration based on saturation with the absorber pressure. The interface temperature at that instant is the maximum temperature observed on the interface of the falling film and is defined as $T_{f \text { max }}$. The corresponding concentration is the lowest water concentration, which is defined as $\mathrm{C}_{\mathrm{a}_{\mathrm{EQ}}}$. Hence, both variables are useful for describing the overall driving forces for heat and mass transfer.

The value $T_{f \max }$ is dependent on the entering concentration, the temperature, and the pressurc of the absorber, and would account for their independent cffects. The entering coolant temperature is the lowest temperature that the film could ideally achieve. Therefore, an overall heat transfer coefficient was defined in terms of the load and this maximum achievable temperature gradient:

$$
\frac{\mathrm{q}}{\mathrm{A}_{\mathrm{o}}}=\mathrm{q}_{\text {wall }}^{\prime \prime} \equiv \mathrm{H}\left(\mathrm{T}_{\mathrm{f}_{\max }}-\mathrm{T}_{\mathrm{CL}_{\mathrm{in}}}\right)
$$

The load can also be defined in terms of the temperature gradient along the wall as

$$
q_{\text {wall }}^{\prime \prime}=-k \frac{d T}{d y} \underset{y=0}{ }
$$

Using the scales of $\overline{\mathrm{T}}=\mathrm{T} /\left(\mathrm{T}_{\mathrm{f}_{\max }}-\mathrm{T}_{\mathrm{Cl}_{\text {}_{\text {in }}}}\right)$ and $\overline{\mathrm{y}}=\mathrm{y} / \mathrm{D}$, and then substituting for the overall heat transfer coefficient from Eq. 2 yields the following overall $\mathrm{Nu}$ number:

$$
\mathrm{Nu} \equiv \frac{\mathrm{HD}_{\mathrm{u}}}{\mathrm{k}_{\mathrm{f}}}=\frac{\left(\mathrm{q}_{\mathrm{wall}}^{\prime \prime}\right) \mathrm{D}_{\mathrm{o}}}{\mathrm{k}_{\mathrm{f}}\left(\mathrm{T}_{\mathrm{f}_{\max }}-\mathrm{T}_{\mathrm{CL}_{\mathrm{in}}}\right)}
$$

Inspection of Eq. 4 shows that the effects of coolant temperature, ahsorher pressure, and solution concentration arc supported implicitly through the defined overall tcmperature gradient. If the entering concentration of vapor pressure increases, then $T_{f \max }$ will increase and account for the larger driving forces.

\section{Mass Transfer}

Care was taken to make sure. the test section operated under vacuum pressure with only trace amounts of non-condensables. Therefore, the gas-film resistance was negligible, and the absorber pressure can he assumed to he imposed on the liquid-vapor interface. We do not, however, assume that the interface is saturated with the absorber pressure because the interface concentration is unknown. The absorption process is liquid-sidecontrolled, and the liquid-side coefficient from the interface to the hulk of the film expresses thc driving force for mass transfer.

At the top of the absorber the concentration is $\mathrm{C}_{\mathrm{a}_{\mathrm{L} Q \mathrm{Q}}}$ The mass diffusivity of aqueous $\mathrm{LiBr}$ is very low, on the order of $10^{-9} \mathrm{~m}^{2} / \mathrm{s}$, and any absorbed mass tends to stay on the interface unless it is mixed into the hulk of the film. The maximum water concentration would he observed at the absorher exit, tied to the film temperature. Therefore, we used an overall concentration driving force based on the continuity of absorbate from the inlet to the exit of the absorber. UsC of the derived driving force avoids the uncertainty at the interface and takes advantage of the fact that the solute, LiBr, remains constant. Hence, we define an overall liquidside mass transfer cocfticient as

$$
\frac{\dot{\mathrm{m}}_{\mathrm{v}}}{\mathrm{A}_{\mathrm{o}}}=\dot{\mathrm{m}}_{\mathrm{v}}^{\prime \prime} \equiv \mathrm{H}_{\mathrm{m}}\left(\mathrm{C}_{\mathrm{a}_{\mathrm{Lx}}}-\mathrm{C}_{\mathrm{il}_{\mathrm{EQ}}}\right)
$$

The mass flux can also be defined in terms of the concentration gradient along the interface as

$$
\dot{\mathrm{m}}_{\mathrm{v}}^{\prime \prime}=-\left.\mathrm{D}_{\mathrm{ab}} \eta^{\prime} \frac{\mathrm{dC_{ \textrm {a } }}}{\mathrm{dy}}\right|_{\mathrm{y}=\Delta}
$$

The scales of $\overline{\mathrm{C}}_{\mathrm{a}}=\mathrm{C}_{\mathrm{a}} /\left(\mathrm{C}_{\mathrm{a}_{\mathrm{e} x}}-\mathrm{C}_{\mathrm{a}_{\mathrm{Eu}}}\right)$ and $\overline{\mathrm{y}}=\mathrm{y} / \mathrm{D}$, arc substituted into Eq. 6 and the overall mass transfer coefficient from Eq. 5 is used to yield the following overall Sh number:

$$
\mathrm{Sh}=\frac{\mathrm{H}_{\mathrm{m}} \mathrm{D}_{\mathrm{o}}}{\mathrm{D}_{\mathrm{ab}}}=\frac{\dot{\mathrm{m}}_{\mathrm{v}}^{\prime \prime} \mathrm{D}_{\mathrm{b}}}{\eta^{\prime}\left(\mathrm{C}_{\mathrm{a}_{\mathrm{ex}}}-\mathrm{C}_{\mathrm{a}_{\mathrm{EQ}}}\right) \mathrm{D}_{\mathrm{ab}}}
$$

Wc defined the overall liquid-side Sh number according to Eq. 7 to avoid use of the equilibrium condition along the interface. Neither the interface temperature nor the concentration are known. and they cannot be determined unless equilibrium is assumed with the absorber pressure. Reductions of liquid coefficients based on 
Eq. 5 showed excellent trending of data, whereas an arithmetic or log-mean concentration difference yielded large scatter because they require interface measurements. Eq. 5 has two unknowns, the mass absorbed and the exit concentration. The concentration of water leaving the absorber can be related to the continuity of the solute and to the continuity of mass as follows:

$$
\mathrm{C}_{\mathrm{a}_{\mathrm{ex}}}=\frac{\rho}{\overline{\eta^{\prime}}}\left[\frac{\dot{\mathrm{m}}_{\mathrm{eq}}\left(1-\mathrm{X}_{\mathrm{ex}}\right)+\dot{\mathrm{m}}_{\mathrm{v}}}{\dot{\mathrm{m}}_{\mathrm{eq}}+\dot{\mathrm{m}}_{\mathrm{v}}}\right]
$$

Given the two equations for the mass absorbed and the exit concentration, both unknowns can be determincd if a suitable correlation for the Sh number is formulated from the data. Diffusivity data is reported by Miller (1998) and is used in calculating the Sh number in Eq. 7.

\section{HEAT AND MASS TRANSFER CORRELATIONS}

The data shown in Fig. I for the load and in Fig. 2 for the mass absorbed were reduced to the $\mathrm{Nu}$ and Sh numbers, and the results are depicted in Fig. 4. All data collapse into a tight trend with the exception of $\mathrm{Nu}$ data for testing at $60 \mathrm{wt} \%$ and $35^{\circ} \mathrm{C}$ coolant. Sh data for $60 \mathrm{wt} \%$ testing fell within the bulk of the data; however, $\mathrm{Nu}$ data for $60 \mathrm{wt} \%$ testing appears as an anomaly in Fig. 4. The data were checked by repeating some testing at 60 wt\%, and the results are shown in Fig. 4 by the + symbols. In fact, these data represent testing that was conducted one month later when testing with the thcrmographic phosphors (Miller and Keyhani 1999). Both 60 wt \% data sets are similar in magnitude and prove that the earlier data are not spurious. All attempts using regression analysis to collapse $\mathrm{Nu}$ data for $60 \mathrm{wt} \%$ testing failed, and therefore, these data were excluded. Only the 62 and 64 wt\% data were included in the regression analysis, and the $60 \mathrm{wt} \%$ data were then compared to the correlations of $\mathrm{Nu}$ and $\mathrm{Sh}$ numbers.

Regression analysis was conducted using statistical application software (SAS). The results for both the $\mathrm{Nu}$ and the Sh numbers are listed in Table 1. The Nu number was correlated as function of the $\mathrm{Pr}, \mathrm{Ka}$, and Ja numbers, while the Sh number was correlated as function of the Sc and Ka numbers. The results of correlating the data arc also depicted in Fig. 5. Here, the $\mathrm{Nu}$ and Sh data are scaled by the regression parameters listed in Table 1. The curve tit, $C_{1} \operatorname{Re}^{\alpha 1}$, is then superimposed onto the scaled data to compare the corrclation to the reduced experimental data. Both correlation and experiment are in excellent agreement, as seen in Fig. 5. Analysis showed that the $\mathrm{Ka}$ number significantly improved the correlation, and its trends were consistent with the regression equation for the $\mathrm{Nt}$ number formulated by Miller (1998). Increasing the Ka number resulted in a decrease in the film thickness, which in turn caused an increase in both the heat and the mass transfer.

Miller (1998) found the Ka exponent in his Nt correlation to be negative (i.e., larger Ka yielding a thinner film). Regression yielded positive exponents for the Ka number in the formulations

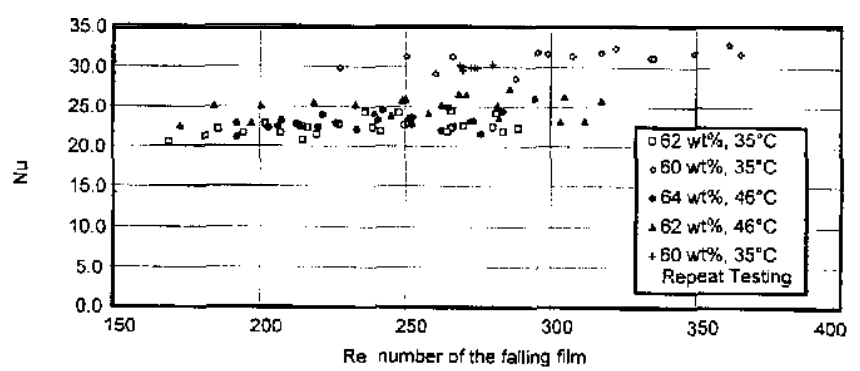

(a) The overall Nu number was calculated using Eq. 4.

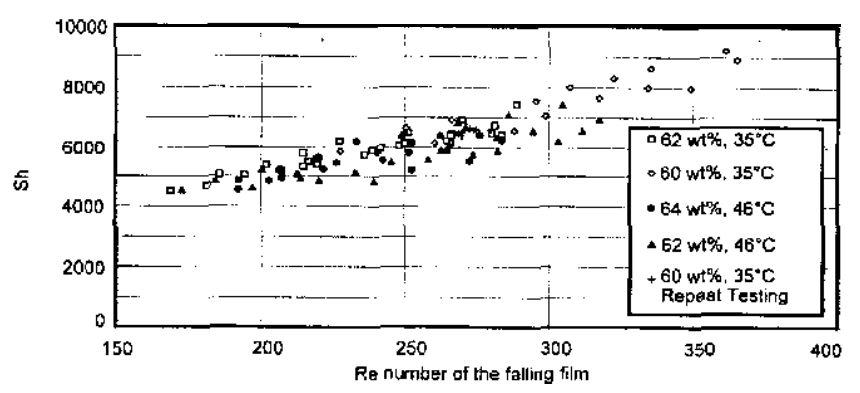

(b) The overall Sh number was calculated using Eq. 7 .

Fig. 4. Overall Nu and Sh numbers as a function of concentration, coolant temperature, and falling film mass flow rate.

for the $\mathrm{Nu}$ and Sh correlations (i.e., larger $\mathrm{Ka}$, thinner film, and increased load and mass absorbed). If the $60 \mathrm{wt} \%$ data were included in the regression, then the correlation parameter For the Ka number was too strong, and it made the $\mathrm{Nu}$ and $\mathrm{Sh}$ correlations somewhat biased by increasing the exponent of $\mathrm{Ka}$ to about 0.8 . The SAS routines showed that the $\mathrm{Nu}$ correlation improved with inclusion of the Ja number; although its regression coefficient is small, it supports the Nu number by helping to account for film-tocoolant temperature effects. The negative coefficient for the Ja number rcflects an increase in $\mathrm{Nu}$ number, which again is consistent with the defined heat transfer coefficient in Eq. 2 (i.e., $\mathrm{H}=\mathrm{q}^{\prime \prime} / \Delta \mathrm{T}$, an increasing Ja number, implics an increasing AT, which in turn implies a tower $\mathrm{Nu}$ ).

The Gratz-Nusselt approach would formulate the $\mathrm{Nu}$ and $\mathrm{Sh}$ correlations in terms of $\mathrm{Pe}_{\mathrm{H}}$ and $\mathrm{Pe}_{\mathrm{M}}$ numbers, which cancels the effect of viscosity. However, regression for the $\mathrm{Nu}$ number showed the coefficient for the Pr number to be significantly different from the coefficient for the Re number. For the Sh number, it was found that the regression yielded similar coefficients for the Re and Sc numbers. Apparently, the effect of viscosity is more pronounced in the $\mathrm{Nu}$ formulation than in the $\mathrm{Sh}$ (Fig. 5). Also, the thermal boundary laycr easily develops within $0.2 \mathrm{~m}$ of the inlet; while the concentration boundary layer requires about $1 \mathrm{~m}$ because of the strength of the Le number. 
Table 1. Heat and mass transfer regression analysis

\begin{tabular}{|c|c|c|}
\hline & \multicolumn{2}{|c|}{ SAS regression analysis results } \\
\hline & Nu number & Sb number \\
\hline 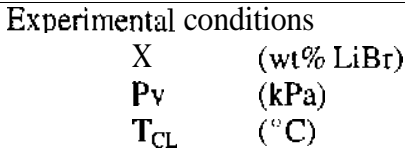 & $\begin{array}{l}62-64 \\
1.0-1.5 \\
3517\end{array}$ & $\begin{array}{r}62-64 \\
1.0-1.5 \\
35-47\end{array}$ \\
\hline $\begin{array}{l}\text { Range of regression variables } \\
\text { Re number } \\
\text { Sc number } \\
\text { Pr number } \\
\text { Ka number } \\
\text { Ja number }\end{array}$ & $\begin{array}{c}100-400 \\
2500-3200 \\
21-25.5 \\
440-550 \\
0.005-0.018\end{array}$ & $\begin{array}{c}100-400 \\
2500-3200 \\
21-25.5 \\
440-550 \\
0.005-0.018\end{array}$ \\
\hline $\begin{array}{l}\text { Regression equation } \\
\text { Coefficients }\end{array}$ & $\begin{array}{c}\mathrm{Nu}=\mathrm{C}_{\mathrm{l}} \operatorname{Re}^{\alpha \mathrm{l}} \mathrm{Pr}^{\alpha 2} \mathrm{Ka}^{\alpha 3} \mathrm{Ja}^{\alpha 4} \\
\mathrm{C}_{\mathrm{l}}=0.8429 \\
\mathrm{al}=0.145664 \\
\mathrm{a} 2=0.048053 \\
\mathrm{a} 3=0.330440 \\
\mathrm{a} 4=4.071242\end{array}$ & $\begin{array}{c}\mathrm{Sh}=\mathrm{C}_{1} \operatorname{Re}^{\alpha 1} \mathrm{Sc}^{\alpha 2} \mathrm{Ka}^{\alpha 3} \\
\mathrm{C},=0.0046 \\
\text { a1 }=0.771119 \\
\text { a2 }=0.771119 \\
\text { a3 }=0.593282\end{array}$ \\
\hline Number of data points & 86 & 86 \\
\hline Average absolute deviation & $3.45 \%$ & $4.28 \%$ \\
\hline Maximum error & & \\
\hline
\end{tabular}

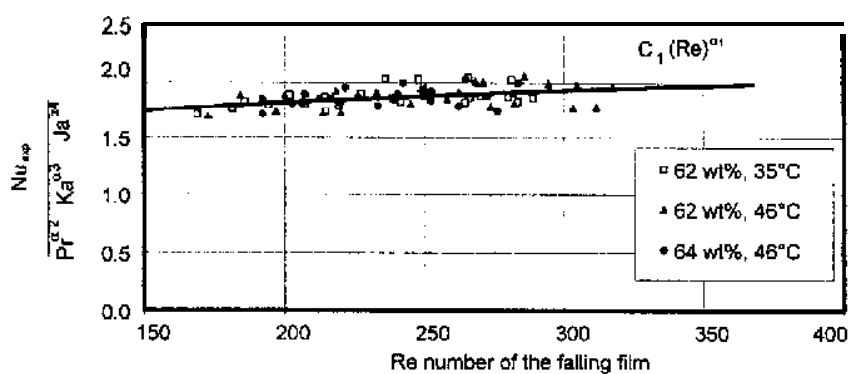

(a) The Nu correlation is compared to experiment.

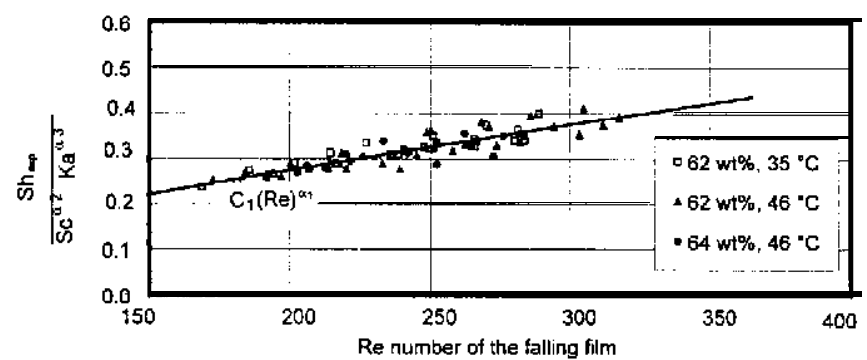

(b) The Sh correlation is compared to experiment.

Fig. 5. Nu and Sh numbers correlated from 62 and $64 \mathbf{w t} \% \mathrm{LiBr}$ data.
A point-by-point review is shown in Fig. 6 for both the $\mathrm{Nu}$ and Sh numbers for all experimental data. The ordinate in both 6(a) and 6(b) is the corrclation, listed in Table 1, divided hy the reduced experimental data. The results prove that the data is well described by the correlations for $\mathrm{Nu}$ and $\mathrm{Sh}$ numbers. The average overall deviation in Nu number is only $3.45 \%$ for the fitted data. The $60 \mathrm{wt} \%$ data for the Nu number is about $17 \%$ less than the experimental value. The Sh correlation has an average overall deviation of only $4.3 \%$ for the fitted data. Inclusion of $60 \mathrm{wt} \% \mathrm{Sh}$ data causes the average error to increase to $6.7 \%$, with the error for the $60 \mathrm{wt} \%$ SH data being about $15 \%$ low of the experimental value. The average error was calculated using the formula

$$
\text { Averaged Error }=\frac{\sum_{j=1}^{N} A B S\left[\frac{1-N u_{\text {corr }, j}}{N u_{\text {exp }, j}}\right]}{N} \text {. }
$$

Runs conducted at $60 \mathrm{wt} \%$ and $35^{\circ} \mathrm{C}$ coolant had the thinnest film as compared to all other data, yet the mass absorbed was comparable to testing at $62 \mathrm{wt} \%$ and $35^{\circ} \mathrm{C}$ coolant (see Fig. 1). It was therefore believed that viscosity and possibly surface tension effects caused the $60 \mathrm{wt} \%$ data to behave differently from the bulk of the data. To demonstrate the effect, the transport properties for testing at $60 \mathrm{wt} \% \mathrm{LiBr}$ were evaluated at concentrations of 50,55 , and $56.5 \mathrm{wt} \% \mathrm{LiBr}$ (i.e., we assumed the mass absorbed had some 


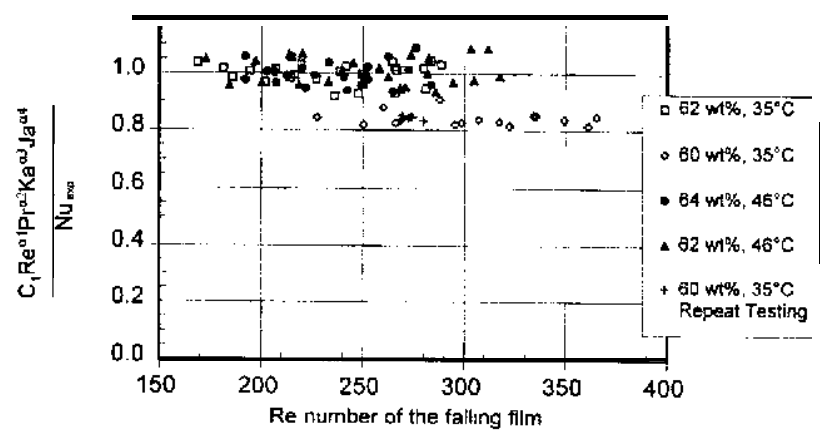

(a) Nu correlation vs experiment.

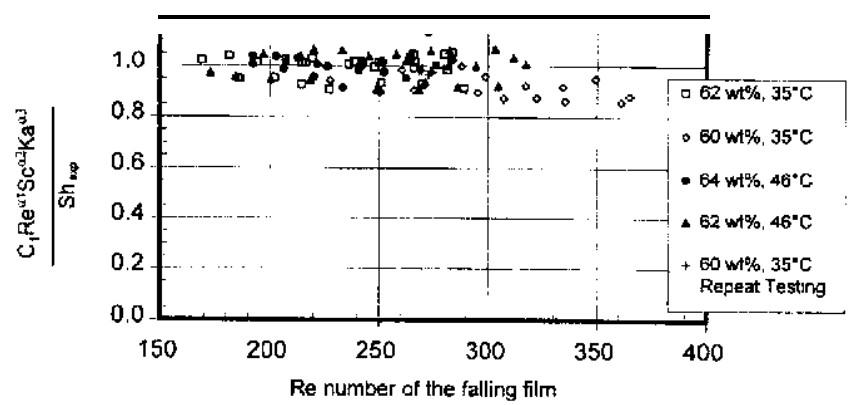

(b) Sh correlation vs experiment.

Fig. 6. Point-by-point review of the error observed in the heat and mass transfer correlations.

variable property effect, and caused a local decrease in both viscosity and surface tension). If the transport properties of viscosity and surface tension were evaluated at about $55 \mathrm{wt} \% \mathrm{LiBr}$ rather than at $60 \mathrm{wt} \%$, then the data closely matched the $\mathrm{Nu}$ correlation curve [Fig. 7(a)]. The results affected both the $\mathrm{Nu}$ and Sh correlations; however, the effect was more pronounced for the $\mathrm{Nu}$ correlation [Fig. 7(a) and (b)].

Wasden and Dukler (1990) had shown that the convective motion of the waves accelerated fluid in the wave front into the mass of the slower substrate. For a hot absorbate, this would force a hotter fluid from the surface into the cooler substrate, thereby creating anomalous temperature gradients. Liquid viscosity, being a strong function of temperature, would drop at the wave front. The less viscous absorbate would be mixed into the substrate and would reduce the viscous shear effect on the wave. Shair (1971) modeled a variable viscosity laminar film and showed that the flow characteristics could be greatly affected by a change in the transport properties within the film. Further, the composition and diffusivity would also be affected by the heat inversion near the wave front. Yih and Seagrave (1980) analyzed gas absorption into liquid films with accompanying chemical reactions. They modeled a. linear temperature drop across the film and varied the viscosity, diffusivity, kinetic rate, and gas solubility. They concluded that

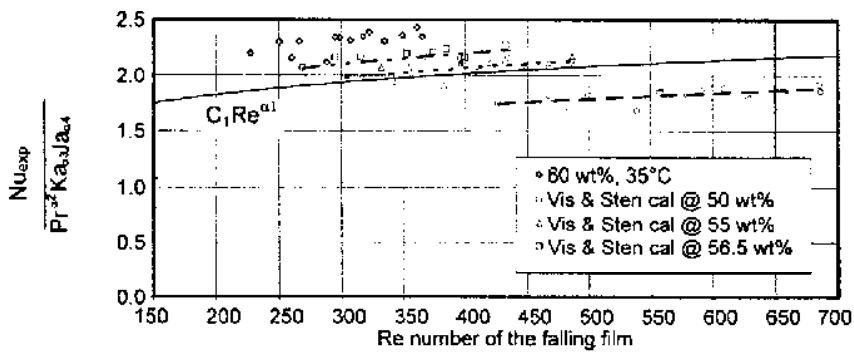

(a) The Nu number for $60 \mathrm{wt} \%$ data correlates best using transport data evaluated at $55 \mathrm{wt} \% \mathrm{LiBr}$.

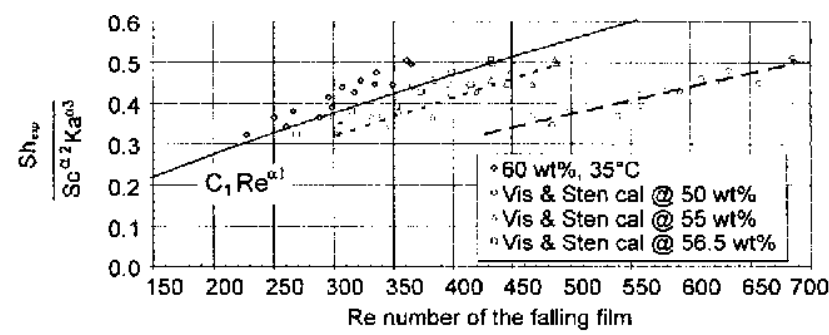

(b) The Sh number for $60 \mathrm{wt} \%$ data correlates best using transport data evaluated at $56.5 \mathrm{wt} \% \mathrm{LiBr}$.

Fig. 7. Simulations to observe the effect of viscosity and surface tension on the $60 \mathrm{wt} \%$ data.

heat transfer had a profound effect on mass transfer and found that an exponential representation was more accurate than an assumed linear profile. Their study is a uselul guide and helps cxplain the anamalous behavior for testing at $60 \mathrm{wt} \%$.

Obscrvations of the wave structure during testing in the miniabsorber differed from those made during the hydrodynamic study of the lalling film. Differences were duc to the effects of absorption. During testing in the mini-absorber at $64 \mathrm{wt} \% \mathrm{LiBr}$, the solution flow was reduced to a point at which it would just wet the entire tube surface. A further decrease, to $0.013 \mathrm{~kg} / \mathrm{s}$, caused the film to break down, and the flow did not wet the entire tube. If the steam valve was closed. the entire surface would rewet within $30 \mathrm{~s}$. Once again, opening the steam valve caused dryout to occur within $30 \mathrm{~s}$. The process was successfully repeated several times. Each time the steam valve was opened, dry-out would occur, not instantancously, but within about $30 \mathrm{~s}$. The results show the strong influence of the absorbate on the hydrodynamics of the falling film. Unfortunately, we did not measure hydrodynamic data during simultaneous heat and mass transfer testing. However, visual observations indicated a larger wave structure during absorption than was observed during the hydrodynamic study. Coupling this observation with the results by Wasden and Dukler (1990) leads to the conclusion that the 
viscosity of the falling film varies non-uniformly through the thickness of the film. The variable viscosity effect causes the waves to slide along a less viscous substrate because of the hot absorbate, which is forced from the surface of the wave front into the bulk of the film. The proposed dynamics would further accelerate the waves and yicld peak-to-substrate ratios larger than those observed during hydrodynamic testing.

\section{VALIDATION AGAINST INDEPENDENT DATA}

Grossman and Alefeld (1996) introduced the brine to the test tube with about IO to $20^{\circ} \mathrm{C}$ of subcooling. In commercial chillers the hrinc is sprayed into the absorber and adiabatically equilibrates with the absorbate vapor prior to hitting the absorber tubes. Therefore, in independent mini-absorber testing, the thermodynamic state of the brine when first exposed to the absorber tube was not as well defined as in the present study. Further, the film-side energy balance best matched the coolant side balance if the temperature and concentration of the entering brine were used in the film-side encrgy balance rather than the equilibrium state based on the absorber pressurc. Hence, for the validations of Grossman and Alefeld the measured entering brine temperature was substituted for the $T_{f \max }$, temperature.

Grossman's data were reduced using Eq. 4 for the Nu number and Eq. 7 for the Sh number. Data were scaled using the correlation regressions, listed in Table I, and plotted in Fig. 8 against the correlation for $\mathrm{Nu}$ and $\mathrm{Sh}$. Grossman's data practically falls right on top of the $\mathrm{Nu}$ and $\mathrm{Sh}$ correlations and further substantiates the accuracy of the correlations formulated from the present study. The results are very promising. Kim et al. (1995) presented a mass transfer correlation based on an approach of gas absorption into a laminar falling film of aqueous $\mathrm{LiBr}$ (Sherwood et al. 1975). Kim's data are plotted on log-log scale and show variation over two decades of the ordinate. By comparison, the correlation presented herein is accurate to within an absolute error of $7 \%$ of extensive experimental data.

\section{CONCLUSIONS}

Experimental data for falling-film absorption are sparse. The dearth of experimental data strongly suggested the need for a combined experimental and analytical approach to the absorption phenomena. The data must be free of the confounding issue of non-condensables and must provide information in the operating ranges of present-day equipment. No litcraturc data are readily available at the design operating conditions of 62 and 64 wt\% $\mathrm{LiBr}$ and 0.7 through $1.5 \mathrm{kPa}$ absorber pressure.

This study provides corrclations for the complex heat and mass transfer process. The correlations are validated against extensive experimental data and contain useful information for guiding the design of a vertical column absorber with no heat and mass transfer additive. The state of the art in absorber design is still maturing because of the strong market influence incurred in the early 1970s. Rules of thumb coupled to empirical data have

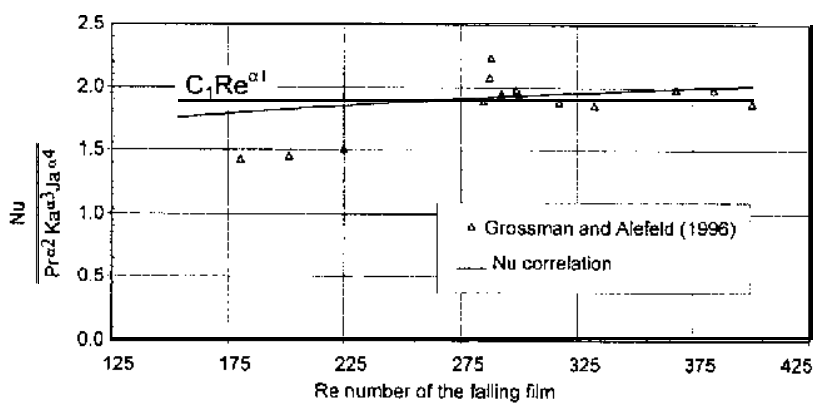

(a) The Nu number predicts Grossman and Alefeld's data.

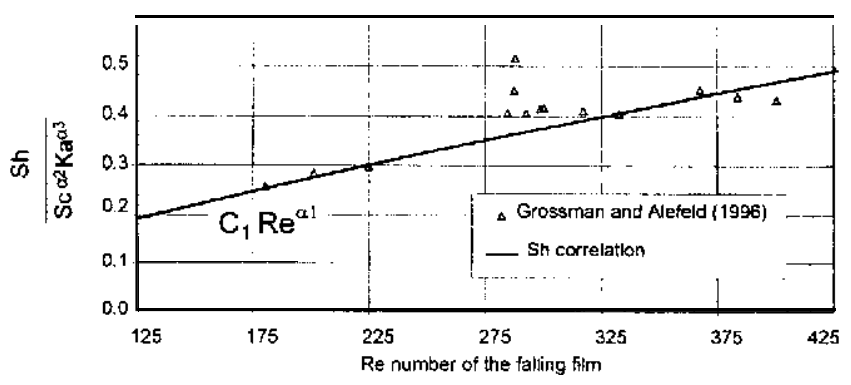

(b) The Sh corretation predicts Grossman and Alefeld's data

Fig. 8. Correlation for Nu and Sh numbers validated against independent data.

led to extrapolations, causing equipment to be overdesigned, heavy, and costly.

The correlation of $\mathrm{Nu}$ and $\mathrm{Sh}$ numbers provides a simple and direct calculation of the load and mass absorbed given the entering conditions for the absorber. The Sh correlation is coupled to the continuity of the solute, and the two independent equations yield the overall mass absorbed. Aqueous $\mathrm{LiBr}$ is a salt solution, and ions rather than molccules diffuse through the liquid. The theory of diffusion of salts at low concentrations is well developed; however, little information is known about the behavior of more concentrated solutions. The Sh correlation accounts for these intermolecular forces by using the diffusivity data measured by Kashiwagi (1985).

Simultaneous heat and mass transfer has strong pressurc, concentration, and temperature effects. The $\mathrm{Nu}$ and $\mathrm{Sh}$ correlations support these effects through the defined heat and mass transport coefficients. Regression analysis revealed the $\mathrm{Ka}$ number as a strong regression parameter; its inclusion significantly improved the correlation of $\mathrm{Nu}$ and $\mathrm{Sh}$ numbers. Its formulation in $\mathrm{Nu}$ and $\mathrm{Sh}$ was consistent with the correlation for $\mathrm{Nt}$ number. An increasing Ka number resulted in a thinner film for wavy-laminar flow, which in turn would increase load and mass absorbed. Miller (1998) had shown the exponent for Ka number was negative in the $\mathrm{Nt}$ correlation; but in $\mathrm{Nu}$ and $\mathrm{Sh}$ correlations, the Ka power was positive and of the same magnitude as in the $\mathrm{Nt}$ 
correlation. The average error, excluding $60 \mathrm{wt} \%$ data, is $\pm 3.5 \%$ for the load and $\pm 4.3 \%$ for the mass absorbed.

The $60 \mathrm{wt} \%$ data was an outlier as compared to data at 62 and $64 \mathrm{wt} \% \mathrm{LiBr}$ because of the variable viscosity effects observed for the $60 \mathrm{wt} \%$ data having the thinnest falling films. Using viscosity and surface tension transport properties evaluated at lower concentrations of $\mathrm{LiBr}$ (about $55.5 \mathrm{wt} \% \mathrm{LiBr}$ ) caused the data to better match the $\mathrm{Nu}$ and $\mathrm{Sh}$ correlation curves. Evaluations at the lower concentration of $55 \mathrm{wt} \% \mathrm{LiBr}$ caused the Re number for $60 \mathrm{wt} \%$ testing to increase to a maximum value of about 450 .

\section{ACKNOWLEDGMENTS}

The research reported herein was sponsored by Dr. Bill Ryan of the Gas Research Institute under contract number 50X9-243. 1844. We thank Ron Fiskum of DOE's Office of Building Equipment and Phil Fairchild and Bob DeVault of ORNL's Energy Division for their support.

\section{REFERENCES}

Bays, G., and McAdams, W. 1973. "Heat Transfer Coefficients in Falling Film Heaters: Streamline Flow." Ind. Eng. Chemistry 29: $1240-46$.

Conlisk, A. T. 1995. "Analytical Solutions for the Heat and Mass Transfer in a Falling Film Absorber." Chem. Eng. Sci. 50, no. 4: $651-60$.

Emmert, R. E., and Pigford, R. L. 1954. "A Study of Gas Absorption in Falling Liquid Films." Chem. Eng. Prog. 50, no. 2: 87-93.

Grigor'yeva, N. I., and Nakoryakov, V. Ye. 1977. "Exact Solution of Combined Heat- and Mass-Transfer Problem during Film Absorption" (in Russian). Inzh-Fiz. Zh. 33, no. 5: 893-98.

Grossman, G. 1982. Simultaneous Hear and Mass Transfer in Absorption of Gases in Laminar Liquid Films. ORNL/TM-8366. Oak Ridge National Laboratory, Oak Ridge, Tenn.

Grossman, G. 1983. "Simultaneous Heat and Mass Transfer in Film Absorption under Laminar Flow." Int. J. Heat Mass Transfer 26, no. 3: 357-70.

Grossman, G., and Alefeld, G. 1996. Investigation of Heat und Mass Transfer in Absorption Heat Pumps. GIF Report, Contract no. 1-0187-100.10191, Technion-Israel Institute of Technology, Haifa, Israel.

Habib, H. M., and Wood, B. D. 1990. "Simultaneous Heat and Mass Transfer for a Falling Film Absorber--The Two Phase Flow Problem." In Solar Engineering, Proceedings of the 12th Annual ASME Int. Solar Energy Conf., ASME, New York, pp. 61-67.

Kashiwagi, T. 1985. "The Activity of Surfactant in HighPerformance Absorhcr and Absorption Enhancement" (in Japanese). Refrigeration (Reito) 60, no. 687: 72-79.
Kim, K. J.; Berman, N. S.; Chau, D.S.C. and Wood, B. D. 1995. "Absorption of Water Vapour into Falling Films of Aqueous Lithium Bromide." Int. J, Refrig. 18, no. 7:486-94.

Miller. W. A. 1998. "The Experimental Analysis of Aqueous Lithium Bromide Vertical Falling Film Absorption.” Ph.D. diss., University of Tennessee, Knoxvillc, Tenn.

Miller, W. A., and Keyhani, M. 1999. "The Experimental Analysis of Local Heat and Mass Transfer Data for Vertical Falling Film Absorption." In Proc. ASME Advanced Energy Systems Division--1999, vol. 39, sess. 7B, Nashville. Tenn.

Morioka. I., and Kiyota, M. 1991. "Absorption of Water Vapor into a Wavy Film of an Aqueous Solution of LiBr." JSME Int. J., Series II, 34, no. 2: 183-88.

Patnaik, V. 1994. "Combined Heat and Mass Transfer in WavyFilm Absorption." Ph.D. diss., Pennsylvania State Univ., University Park, Penn.

Patnaik, V., and Perez-Blanco, H. 1996. "A Study of Absorption Enhancement by Wavy Film Flows." Int. J. Hear and Fluid Flow 17:71-77.

Seban, R. A., and Faghri, A. 1978. "Wave Effects on the Transport to Falling Laminar Liquid Films." J. Hear Transfer 100:143-47.

Shair, F. H. 1971. "Dispersion in Laminar Flowing Liquid Films Involving Heat Transfer and Interfacial Shear." AIChE J. 17, no. 4: 920-26.

Sherwood, T. K.; Pigford, R. L.; and Wilke, C. R. 1975. Muss Transfer. McGraw-Hill, New York.

Wasden, F. K, and Dukler, A. E. 1990. "A Numerical Study of Mass Transfer in Free Falling Wavy Films." AIChE J. 36, no. Y: 1379-90.

Wekken, B. J. C. van der, and Wassenaar, R. H. 1988. "Simultaneous Heat and Mass Transfer Accompanying Absorption in Laminar Flow over a Cooled Wall." Int. J. Refrig. 11, no. 2: 70-77.

Yang, R., and Jou, D. 1993. "Heat and Mass Transfer on the Wavy Film Absorption Process." Can. J. Chem. Eng. 71:533-38.

Yang, R., and Wood, B. D. 1992. "A Numerical Modeling of an Ahsorption Process on a Liquid Falling Film." Solar Energy 48, no. 3: 195-98.

Yih, S. M., and Chen, K. Y. 1982. "Gas Absorption into Wavy and Turbulent Falling Liquid Films in a Wetted-Wall Column." Chem. Eng. Comm. 17:123-36.

Yih, S. M., and Seagrave, R. C. 1980. "Mass Transfer in Laminar Falling Liquid Films with Accompanying Hcat Transfer and Interfacial Shear." Int. J. Hear Mass Transfer 23:749-57. 